\title{
Effect of Baicalein on GLUT4 Translocation in Adipocytes of Diet-Induced Obese Mice
}

\author{
Wen Min ${ }^{a} \quad$ Mingjie Wu $u^{a} \quad$ Penghua Fang ${ }^{a, c} \quad$ Mei Yuc Mingyi Shic \\ Zhenwen Zhang ${ }^{b}$ Ping Bo ${ }^{b, c}$ \\ aDepartment of Clinical Medical College, Nanjing University of Chinese Medicine, Nanjing, Jiangsu, \\ ${ }^{b}$ Department of Endocrinology, Clinical Medical College, Yangzhou University, Yangzhou, Jiangsu, \\ cJiangsu Key Laboratory of Integrated Traditional Chinese and Western Medicine for Prevention and \\ Treatment of Senile Diseases, Medical College, Yangzhou University, Yangzhou, China
}

\section{Key Words}

Baicalein • GLUT4 • Adipocytes

\begin{abstract}
Background/Aims: Although baicalein has been shown to increase insulin sensitivity in liver of mice, there is no literature available about the effect of baicalein on glucose transporter 4 (GLUT4) translocation from intracellular membrane pools to plasma membranes in adipocytes of diet-induced obese mice. Methods: In the present study, the obese model was induced in mice fed a high fat diet ( $20 \%$ carbohydrates, $21 \%$ protein and $59 \%$ fat) for 16 weeks. The diet-induced obese mice were given $20 \mathrm{mg} / \mathrm{kg}$ baicalein intraperitoneally (i.p.) once a day for 21 days. The plasma insulin was measured by enzyme-linked immunosorbent assay. Fasting blood glucose and insulin resistance indexes were measured by glucose tolerance test (GTT). The expression levels of PGC- $1 \alpha$, UCP1, GLUT4, PPAR $\gamma$, PP38MAPK, pERK and pAKT in adipocytes were determined by quantitative real-time polymerase chain reaction and western blotting. Results: The present findings showed that administration of baicalein decreased pP38MAPK, pERK and PPARy levels, but enhanced pAKT, PGC-1 $\alpha$ and UCP1 contents as well as GLUT4 expression in adipocytes, and reversed high fat diet-induced glucose intolerance, hyperglycemia and insulin resistance in diet-induced obese mice. Moreover, baicalein treatment increased GLUT4 concentration in plasma membranes of adipocytes, i.e. baicalein may prevent insulin resistance through the GLUT4 translocation from intracellular membrane compartments to plasma membranes in adipocytes. Conclusion: These results suggest that baicalein is a powerful and promising agent for treatment of obesity and insulin resistance via Akt/GLUT4 pathway.

W. Min, M. Wu and P. Fang contributed equally to this work.

\begin{tabular}{ll}
\hline Zhenwen Zhang & Department of Endocrinology, Clinical Medical College, Yangzhou University \\
and Ping Bo & Yangzhou, 225001 (China) \\
& E-Mail physiolpep@sina.cn; boping@yzu.edu.cn
\end{tabular}




\section{Cellular Physiology Cell Physiol Biochem 2018;50:426-436

 \\ Min et al.: Baicalein and Adipocytes}

\section{Introduction}

It has been clearly established that by a way of activating the glucose transporter 4 (GLUT4), insulin plays an essential role in glucose transport into adipocytes [1]. In adipocytespecific GLUT4 knockout mice, glucose homeostasis is impaired and insulin resistance develops [2], while adipose tissue-specific GLUT4 over-expression mice exhibit improved insulin sensitivity and glucose homeostasis, even in obese and diabetic mice [3, 4]. Besides, during insulin resistance or type 2 diabetes, GLUT4 translocation to the plasma membrane is impaired [5]. An increase in the glucose transport amount is paralleled by the increase in GLUT4 density at cell plasma membranes [6], i.e. the increase in insulin sensitivity is mediated by translocation of more GLUT4 to the cell surface in response to insulin stimuli. Therefore, these findings have demonstrated that promotion of GLUT4 expression and translocation is essential for the maintenance of glucose homeostasis in the management of insulin resistance and type 2 diabetes.

Baicalein is a polyphenolic compound and a major bioactive flavonoid extracts from Scutellaria baicalensis [7]. A few studies reported that baicalein exhibits the anti-obesity, anti-diabetic, antioxidant and anti-inflammatory activities [8-12]. Baicalein was reported to have antihyperglycemic effects through the improvement of islet $\beta$-cell survival and mass [8]. Moreover, it was also found that treatment with baicalein to diabetes obviously stimulated the pPI3K and pAkt and inhibited the level of pGSK3 $\beta$ [11]. Additionally, the previous work verified that baicalein has been shown to increase insulin sensitivity in livers of diet-induced obese mice by blocking of AMPK-mediated MAPKs pathway [12]. Nevertheless, there are few reports about the effect of baicalein on insulin sensitivity and GLUT4 function of transporting glucose into adipocytes. So we used diet-induced obese mice to evaluate the effect of baicalein on GLUT4 function of glucose transportation in adipocytes.

\section{Materials and Methods}

Drugs and reagents

Baicalein was purchased from Sigma-Aldrich, USA. Antibodies against P38MAPK (Cat. No. 9212), pP38MAPK (Cat. No. 4511), Akt (Cat. No. 4691), pAkt (Cat. No. 9271), ERK (Cat. No. 4695), pERK (Cat. No. 4377), Na, K-ATPase (Cat. No. 3010), UCP1 (Cat. No. 14670) and PPAR $\gamma$ (Cat. No. 2430) were acquired from Cell Signaling Technology Inc, USA. Antibodies against GLUT4 (Cat. No. 07-1404), and peroxisome proliferator-activated receptor- $\gamma$ coactivator- $1 \alpha$ (PGC-1 $\alpha$ ) (Cat. No. ST-1202) from Merck Millipore Inc, Germany. Antibodies against tubulin (Cat. No. BM1453) from BOSTER Inc, China. Insulin ELISA kits from Uscn Life Science, Inc. Wuhan, China.

\section{Animals}

All animal experiments were carried out in accordance with the guidelines of the Animal Care and Use Committee of Yangzhou University. Six-week-old male C57BL/6J mice were kept in a standard laboratory condition of temperature $21 \pm 2{ }^{\circ} \mathrm{C}$, relative humidity $50 \pm 15 \%, 12$ hour light-dark cycles, with water and food available ad libitum. All animals used were closely monitored to ensure that none lived through stress and discomfort. The mice were fed a high fat diet (20\% carbohydrates, $21 \%$ protein and 59\% fat) for 16 weeks. Then the obese mice were divided into two groups: obese control group $(n=8)$ and obese group with baicalein ( $n=8)$. Besides, a normal diet group $(n=8)$ was set up. The mice in the obese group with baicalein were given $20 \mathrm{mg} / \mathrm{kg}$ baicalein intraperitoneally (i.p.) once a day for continuous 21 days at 6:00 am [13]. All controls were given vehicle (DMSO) i.p. The body weight of all mice was recorded every day. Food intake was monitored weekly throughout the experiments. At the end of the experiment, all mice were fasted for $12 \mathrm{~h}$ and used for glucose tolerance test as described below. All animals received human care and all study protocols were approved by the Animal Studies Committee of Yangzhou University. 


\section{Cellular Physiology Cell Physiol Biochem 2018;50:426-436 and Biochemistry Published \begin{tabular}{l|l} 
DOI: 10.1159/000494154 & (c) 2018 The Author(s). Published by S. Karger AG, Basel \\
www.karger.com/cpb
\end{tabular} \\ Min et al.: Baicalein and Adipocytes}

\section{Glucose tolerance test}

After fasted for $12 \mathrm{~h}, 1.5 \mathrm{~g} / \mathrm{kg}$ glucose dissolved in sterile water was i.p. injected into the mice after an overnight fast (12 h). The blood glucose levels in the tail vein blood were monitored at $0,15,30,60$ and 120 min after the glucose challenge using a Glucometer (HMD Biomedical, Taiwan). The areas under the curve (AUC) were calculated according to the formula [(FBG + BG $30 \mathrm{~min}) \times 15 / 60+(B G 30 \mathrm{~min}+\mathrm{BG}$ $60 \mathrm{~min}) \times 15 / 60+(B G 60 \mathrm{~min}+\mathrm{BG} 120 \mathrm{~min}) \times 30 / 60]$. Fasting insulin challenge using competitive insulin ELISA kits according to the manufacturer's specification. The assay range for insulin was $123.5-10000 \mathrm{pg} /$ $\mathrm{ml}$, and intra-assay precision CV\% $<10 \%$ and inter-assay precision CV\% $<12 \%$. The homeostasis model of insulin resistance (HOMA-IR) was calculated by fasting serum insulin concentration $(\mathrm{mU} / \mathrm{ml}) \times$ fasting blood glucose level (mmol/L)/22.5. All measurements were performed in duplicate and the mean of two measurements was considered.

\section{Collection of blood sample and adipose tissue}

After fasted for $24 \mathrm{~h}$ all animals were sacrificed on the second day after the glucose tolerance test. Then $1 \mathrm{ml}$ blood and all adipose tissues were fast collected. The blood samples were centrifugated at 3500 r.p.m. for $10 \mathrm{~min}$ to obtain the plasma which was stored at $-80^{\circ} \mathrm{C}$ until further analysis. The adipose tissues were rinsed, weighed and frozen at $-80^{\circ} \mathrm{C}$ too. This experiment was performed with the specific acceptance of the Animal Studies Committee of Yangzhou University.

\section{Total RNA extraction and real-time PCR}

Total RNA was extracted with Trizol from $100 \mathrm{mg}$ epididymal fat pads. The RNA concentration was calculated by spectrophotometric assays of $260 / 280 \mathrm{~nm}$, and the RNA integrity was assessed by running samples on a $1 \%$ formaldehyde agarose gel in TAE buffer ( $40 \mathrm{mmol} / \mathrm{L}$ tris-acetic acid, $1 \mathrm{mmol} / \mathrm{L}$ EDTA). cDNA was synthesized from $1 \mu \mathrm{g}$ RNA using MMLV reverse transcriptase. Real-time quantitative PCR was performed for gene expression levels using real-time fluorescent detection in an Applied Biosystems 7500 real-time PCR instrument (ABI 7500, USA). The oligonucleotide primers were as follows: GLUT4 Forward Sequence 5'- GGCTTTGTGGCCTTCTTTGAG-3', Reverse Sequence5'- GACCCATAGCATCCGCAACAT-3'; PGC-1 $\alpha$ Forward Sequence 5'-ACCATGACTACTGTCAGTCACTC-3', Reverse Sequence 5'-GTCACAGGAGGCATCTTTGAAG-3'; UCP1 Forward Sequence 5'- CTGGGCTTAACGGGTCCTC-3', Reverse Sequence 5'-CTGGGCTAGGTAGTGCCAGTG-3'; PPAR $\gamma$ Forward Sequence 5'-AAGGCGAGGGCGATCTTG-3', Reverse Sequence 5'-ATCATTAAGGAATTCATGTCGTAGATGAC -3'; GAPDH Forward Sequence 5'AGAACATCATCCCTGCATCC -3', Reverse Sequence5' - TCCACCACCCTGTTGCTGTA - 3'. Amplification condition was: an initial denaturation at $95^{\circ} \mathrm{C}$ for $10 \mathrm{~min}$; $95^{\circ} \mathrm{C}$ for $15 \mathrm{~s}, 62^{\circ} \mathrm{C}$ for $60 \mathrm{~s}, 40$ cycles. The $2^{-\triangle \mathrm{CT}}$ method was used to analyze the PCR data. GAPDH was used as an endogenous housekeeping gene.

\section{Subcellular fractionation of adipocytes}

Membranes of adipocytes were fractionated as described previously [14]. Briefly, the epididymal fat pads were washed, minced and homogenized in ice-cold homogenization buffer $(250 \mathrm{mmol} /$ lsucrose, $2 \mathrm{mmol} / \mathrm{l}$ EDTA, $2.5 \mathrm{mmol} / \mathrm{l}$ Tris-HCl, $10 \mu \mathrm{g} / \mathrm{ml}$ aprotinin, $10 \mu \mathrm{g} / \mathrm{ml}$ leupeptin, and $100 \mu \mathrm{mol} / \mathrm{l}$ phenylmethylsulfonyl fluoride, $\mathrm{pH}$ 7.4), and then centrifuged at $13,000 \mathrm{~g}$ for $20 \mathrm{~min}$ at $4{ }^{\circ} \mathrm{C}$ to remove the fat cake. The infranatant was centrifuged at $31,000 \mathrm{~g}$ for $1 \mathrm{~h}$ to yield the low-density intracellular membranes. The pellet from the first spin was layered over a sucrose cushion and centrifuged at 75, $000 \mathrm{~g}$ for $1 \mathrm{~h}$. The interphase was removed and spun at 39, $000 \mathrm{~g}$ for $20 \mathrm{~min}$ to yield the plasma membranes.

Western blot analysis

Total proteins of epididymal fat pads were extracted using RIPA agents and quantified with BCA protein assay kit to determine protein levels. Briefly, fifty micrograms of samples were separated by a $12 \%$ sodium dodecyl sulfate-polyacrylamide gel electrophoresis and transferred to a polyvinylidene difluoride filter membranes. Membranes were blocked in Tris-buffered saline (pH 7.5) containing 0.05\% Tween-20 $\left(1 \times\right.$ TBST) and $5 \%$ skimmed milk for $2 \mathrm{~h}$, then probed overnight at $4^{\circ} \mathrm{C}$ with an antibody against Na, K-ATPase, GLUT4, Tubulin, P38MAPK, AKT, ERK, pP38MAPK, pAKT, pERK, PGC-1 $\alpha$, UCP1 and PPAR $\gamma$ respectively. Membranes were washed with $1 \times$ TBST for $10 \mathrm{~min}$ and incubated for $2 \mathrm{~h}$ with horseradish peroxidaseconjugated secondary antibody. Lastly, immunoreactive bands were visualized by chemiluminescence and quantified by densitometry using a Quantity One Analysis Software (Bio-Rad).

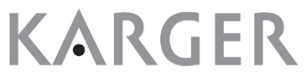




\section{Cellular Physiology Cell Physiol Biochem 2018;50:426-436 and Biochemistry \begin{tabular}{l|l} 
DOI: 10.1159/000494154 & (c) 2018 The Author(s). Published by S. Karger AG, Basel \\
www.karger.com/cpb
\end{tabular} \\ Min et al.: Baicalein and Adipocytes}

Statistical analysis

SPSS 17.0 for Windows was used for statistical analysis. Comparisons between the means of three groups were analyzed by one-way ANOVA with Duncan's tests. Data were presented as mean \pm SEM with $\mathrm{P}<0.05$ as the limit for statistical significance.

\section{Results}

Body weight and weight of whole adipose tissues as well as food intake

All of the six-week-old mice used in this experiment exhibited similar body weight at the beginning of the experiment. Feeding of a high fat diet for 12 weeks enhanced body weight of the mice in obese control and baicalein groups compared with the normal diet group before the administration of baicalein (Fig. 1). As shown in Fig. 1 and Fig. 2 the body weight and weight of whole adipose tissues at 21 days were significantly decreased by $13.2 \%(\mathrm{P}<0.05)$ and $20.1 \%(P<0.05)$ in the baicalein group compared with the obese controls, but increased by $51.2 \%(\mathrm{P}<$ $0.01)$ and $468.3 \%(\mathrm{P}<0.01)$ in the obese control group compared with the normal controls, respectively. As shown in Fig. 3, the food intake of mice was significantly decreased by $37.5 \%(\mathrm{P}<0.01), 17.8 \%(\mathrm{P}>0.05)$ and $37.5 \%(\mathrm{P}<0.01)$ in the baicalein group compared with the obese controls, and by $87.3 \%(\mathrm{P}<0.01)$, 77.1\% $(\mathrm{P}<0.01)$ and $81.3 \%(\mathrm{P}<0.01)$ in the obese control group compared with the normal controls in the first, second and third week, respectively.

\section{Glucose tolerance test}

During the glucose tolerance test, as shown in Fig. 4A, the circulating glucose levels were markedly decreased by $23.6 \%, 13.1 \%$ and $19.8 \%$ at $0 \mathrm{~min}(\mathrm{P}<0.01), 60 \mathrm{~min}(\mathrm{P}>0.05)$ and 120 min $(\mathrm{P}<0.05)$ in the baicalein group compared with obese controls, but increased by $45.7 \%, 20 \%$ and $81.8 \%$ at $0 \min (\mathrm{P}<0.01), 60 \min (\mathrm{P}<0.05)$ and $120 \mathrm{~min}(\mathrm{P}<0.01)$ in the obese control group compared with normal controls, respectively. As shown in Fig. 4B, the areas of glucose tolerance were significantly decreased by $12.8(\mathrm{P}<0.05)$ in the baicalein group compared with the obese controls, but increased by $32.6 \%(\mathrm{P}<0.05)$ in the obese control group compared with normal controls.

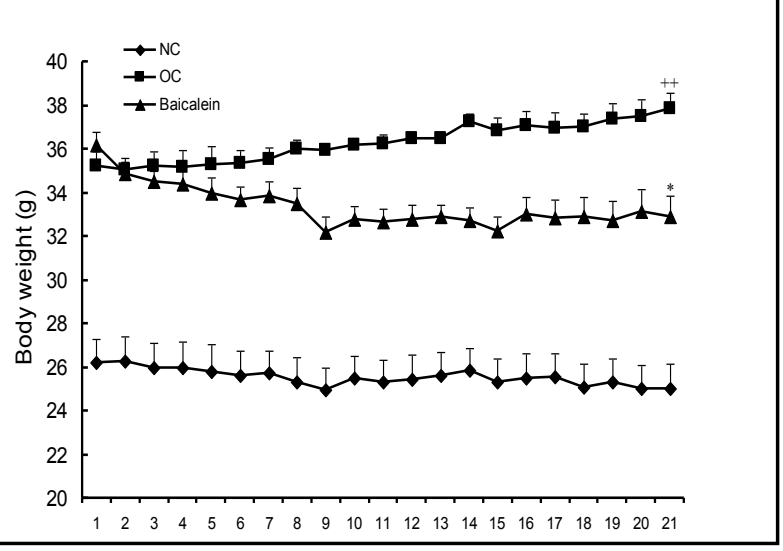

Fig. 1. The i.p. administration of baicalein for 21 days decreased the body weight of high fat diet-induced obese mice $(n=8)$. The body weight was lower in the obese group with baicalein than the obese controls (OC), but higher in OC than the normal controls (NC). All data shown are the means \pm SEM. $* \mathrm{P}<0.05$ vs. $\mathrm{OC} ;++\mathrm{P}<0.01$ vs. NC.



Fig. 2. The i.p. administration of baicalein for 21 days decreased the weight of adipose tissues of high fat dietnduced obese mice $(n=8)$. The weight of adipose tissues controls (OC). All data shown are the means \pm SEM. $* \mathrm{P}<0.05$ vs. $\mathrm{OC} ;++\mathrm{P}<0.01$ vs. NC. was lower in the obese group with baicalein than the obese 
Fig. 3. The i.p. injection of baicalein significantly decreased the food intake of animals $(n=8)$. The food intake of mice in the baicalein group compared with obese controls (OC) was significantly decreased in the first, second and third week respectively. All data shown are the means \pm SEM. ${ }^{* *} \mathrm{P}<0.01$ vs. $\mathrm{OC} ;++\mathrm{P}<0.01$ vs. NC.
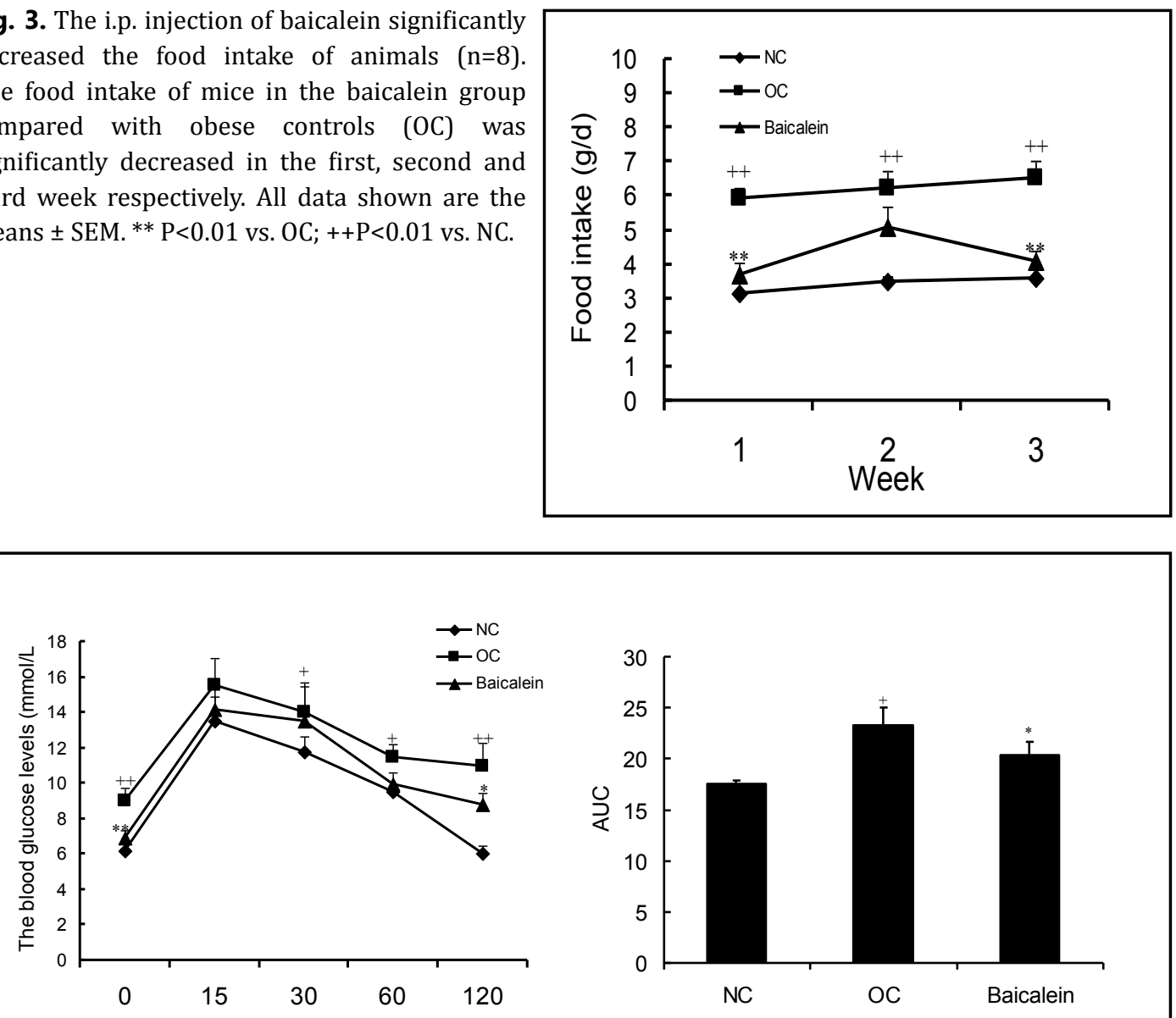

Fig. 4. The i.p. administration of baicalein significantly decreased circulating glucose levels and AUC during the glucose tolerance test $(n=8)$. As shown in Fig. 4A, the circulating glucose levels were markedly decreased at 0 and $120 \mathrm{~min}$ in the obese group with baicalein compared with the obese controls (OC), but increased at 0,60 and $120 \mathrm{~min}$ in the obese control group compared with the normal controls (NC). As shown in Fig. 4B, the areas of glucose tolerance were significantly decreased in the baicalein group compared with the obese controls, but increased in the obese control group compared with normal controls. All data shown are the means \pm SEM. ${ }^{*} \mathrm{P}<0.05 \& * * \mathrm{P}<0.01$ vs. OC $;+\mathrm{P}<0.05 \&++\mathrm{P}<0.01$ vs. NC.

\section{HOMA-IR index}

As shown in Fig. 5, The blood insulin and glucose levels was decreased by $8.1 \%$ (P > $0.05)$ and $21.6 \%(\mathrm{P}<0.01)$ in the baicalein group compared with the obese controls, but elevated by $52.0 \%(\mathrm{P}<0.01)$ and $38.3 \%(\mathrm{P}<0.01)$ in the obese control group compared with the normal controls (Fig. 5A and Fig. 5B). HOMA-IR index of mice was significantly decreased by $27.9 \%(\mathrm{P}<0.01)$ in the baicalein group compared with obese controls, but increased by $110.1 \%(\mathrm{P}<0.01)$ in the obese control group compared with normal controls.

PGC-1 $\alpha$ mRNA, UCP1 mRNA and PPAR- $\gamma$ mRNA expression levels of epididymal fat tissues

As shown in Fig. 6, the PGC-1 $\alpha$ mRNA and UCP1 mRNA expression levels were increased by $160 \%(\mathrm{P}<0.01)$ and $375 \%(\mathrm{P}<0.01)$ in baicalein group compared with obese controls, but decreased by 79.1\% $(\mathrm{P}<0.01)$ and $91.6 \%(\mathrm{P}<0.01)$ in the obese control group compared with the normal controls, respectively. Besides, the PPAR $\gamma$ mRNA expression level was reduced by $66.5 \%(\mathrm{P}<0.01)$ in baicalein group compared with obese controls, but increased by $1156 \%(\mathrm{P}<0.01)$ in the obese control group compared with the normal controls, respectively (Fig. 6). 


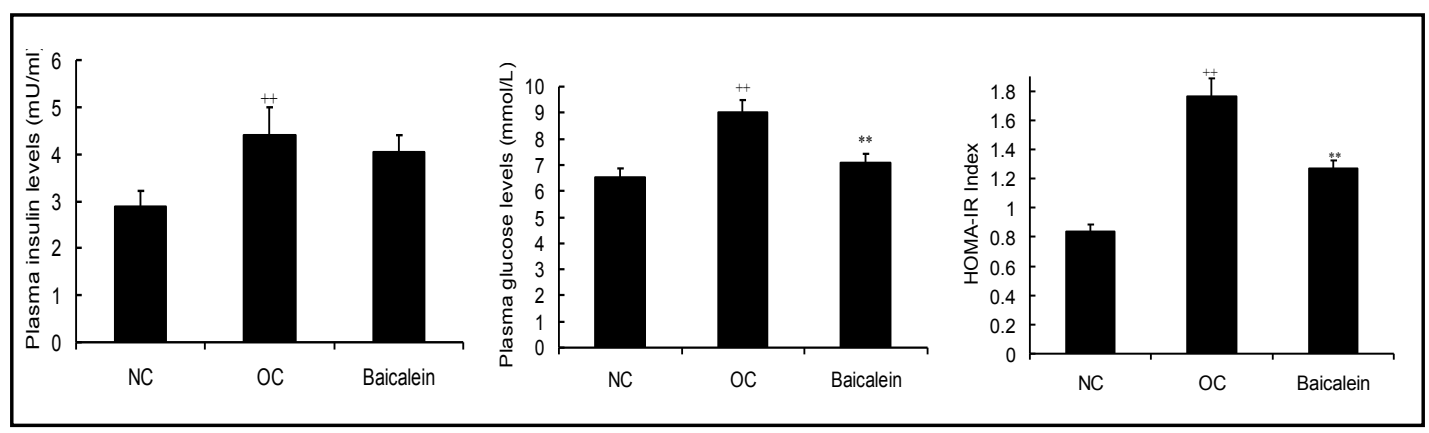

Fig. 5. The i.p. injection of baicalein significantly decreased the HOMA-IR index in animals (n=8). HOMA-IR index in the baicalein group was significantly decreased compared with obese the controls (OC), but that increased in OC compared with normal controls (NC). The blood insulin and glucose levels were lower in the baicalein group than OC, but higher in OC than NC. All data shown are the means \pm SEM. $* \mathrm{P}<0.05 \&^{* *} \mathrm{P}<0.01$ vs. $\mathrm{OC} ;+\mathrm{P}<0.05 \&++\mathrm{P}<0.01$ vs. NC.

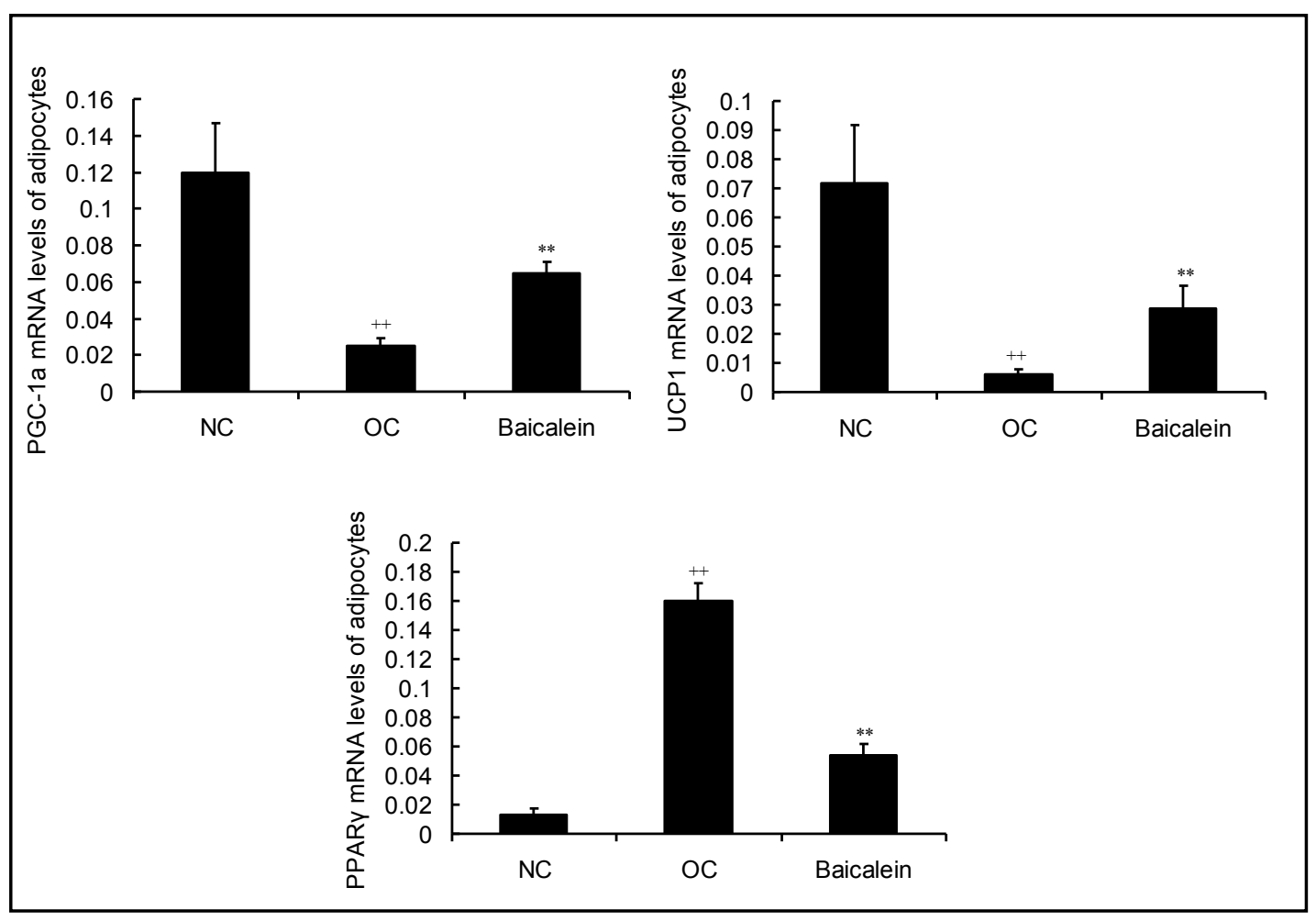

Fig. 6. The i.p. injection of baicalein significantly increased PGC-1 $\alpha$ mRNA and UCP1 mRNA levels, but reduced PPAR $\gamma$ mRNA level in adipocytes of epididymal fat tissues $(n=3)$. The PGC- $1 \alpha$ mRNA and UCP1 mRNA levels were increased in the baicalein group compared with the obese controls (OC), but decreased in OC compared with the normal controls (NC) in adipocytes of epididymal fat tissues. The PPAR $\gamma$ mRNA level was decreased in the baicalein group compared with the obese controls (OC), but increased in OC compared with the normal controls (NC) in adipocytes of epididymal fat tissues. All data shown are the means \pm SEM. ** $\mathrm{P}<0.01$ vs. $\mathrm{OC} ;++\mathrm{P}<0.01$ vs. NC. 


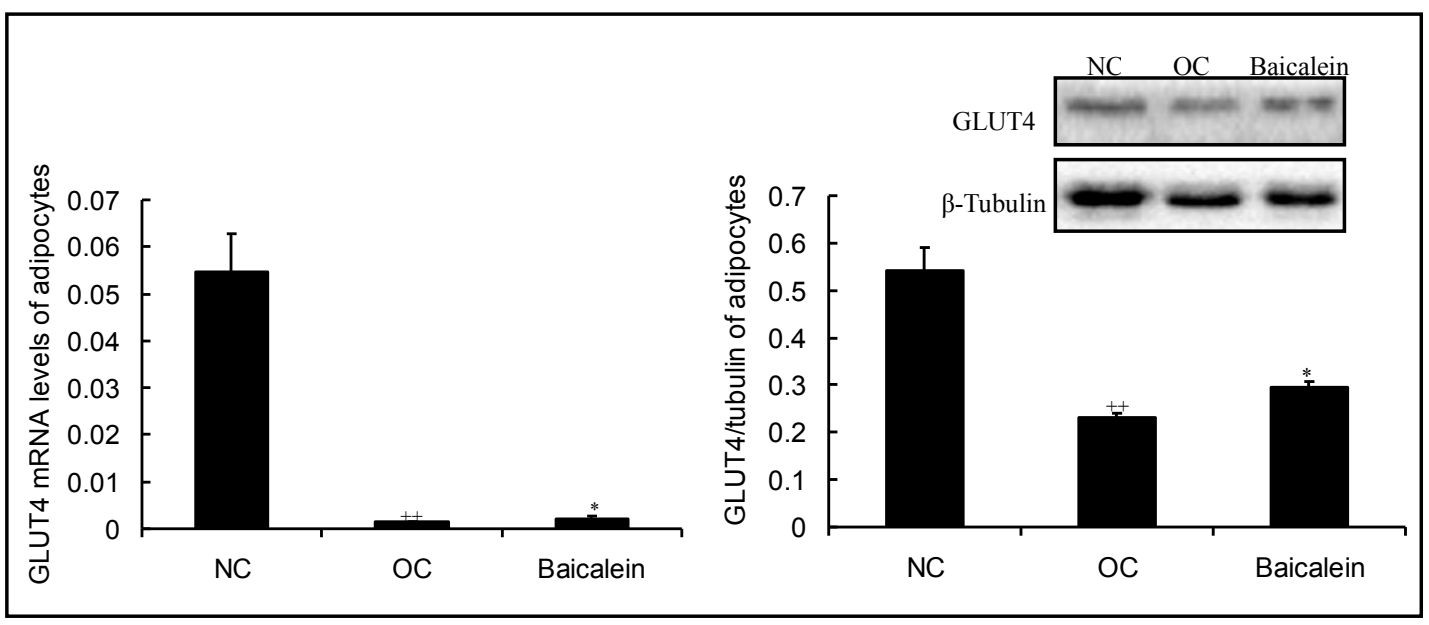

Fig. 7. The i.p. injection of baicalein significantly increased GLUT4 mRNA and GLUT4 contents in adipocytes of epididymal fat tissues ( $n=3$ ). The GLUT4 mRNA and GLUT4 contents were increased in the baicalein group compared with the obese controls (OC), but decreased in OC compared with the normal controls (NC) in adipocytes of epididymal fat tissues. All data shown are the means $\pm \mathrm{SEM}$. ${ }^{*} \mathrm{P}<0.05$ vs. $0 \mathrm{C}$; ${ }^{* *} \mathrm{P}<0.01$ vs. OC; $++\mathrm{P}<0.01$ vs. NC.

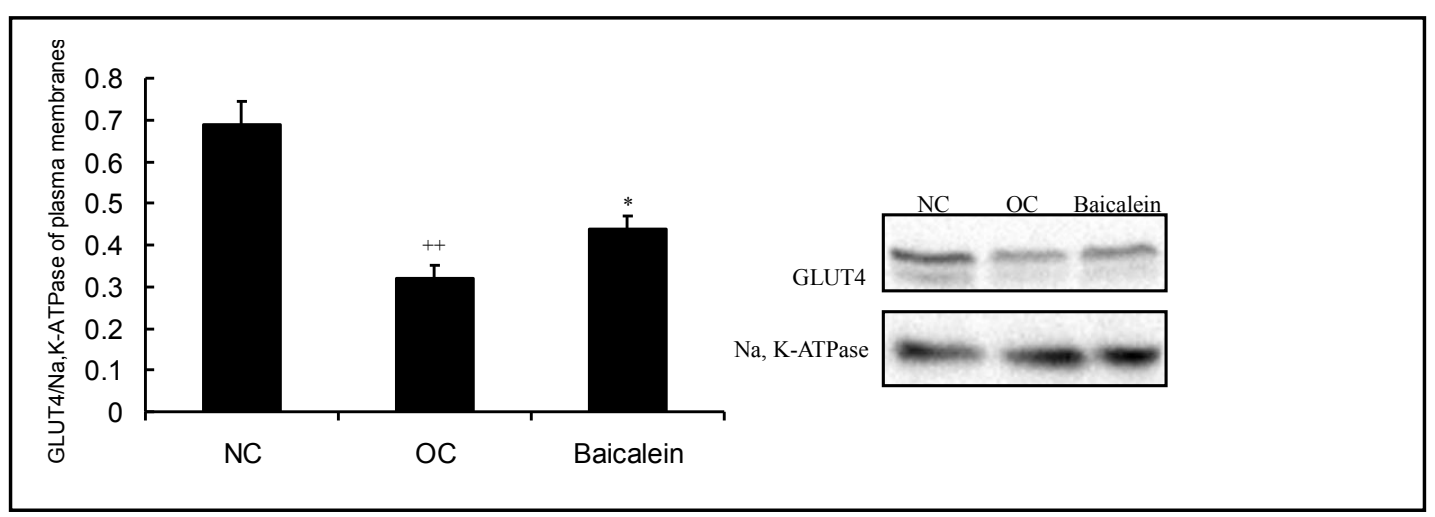

Fig. 8. The i.p. injection of baicalein significantly increased GLUT4 protein levels in plasma membranes of adipocytes $(n=3)$. The GLUT4 protein levels in the plasma membranes were increased in the baicalein group compared with the obese controls (OC), but decreased in OC compared with the normal controls (NC) in the plasma membranes of adipocytes. All data shown are the means $\pm \mathrm{SEM}$. ${ }^{*} \mathrm{P}<0.05$ vs. $\mathrm{OC}$; ${ }^{* *} \mathrm{P}<0.01$ vs. $\mathrm{OC}$; $++\mathrm{P}<0.01$ vs. NC.

\section{GLUT4 mRNA expression levels as well as GLUT4 contents of epididymal fat tissues}

As shown in Fig. 7, the GLUT4 mRNA expression levels were increased by $38.7 \%(\mathrm{P}<$ $0.05)$ in baicalein group compared with obese controls, but decreased by $97.4 \%(\mathrm{P}<0.01)$ in the obese control group compared with the normal controls, respectively. The GLUT4 protein level was elevated by $28.9 \%(\mathrm{P}<0.05)$ in adipocytes of the baicalein group compared with the obese controls, but decreased by $57.5 \%(\mathrm{P}<0.01)$ in the obese control group compared with the normal controls (Fig. 7).

\section{GLUT4 translocation levels in adipocytes of epididymal fat tissues}

As shown in Fig. 8, the GLUT4 protein levels in the plasma membranes were increased by $37.5 \%(\mathrm{P}<0.05)$ in baicalein group compared with obese controls, but decreased by $53.6 \%(\mathrm{P}<0.01)$ in the obese control group compared with the normal controls, respectively (Fig. 8). 


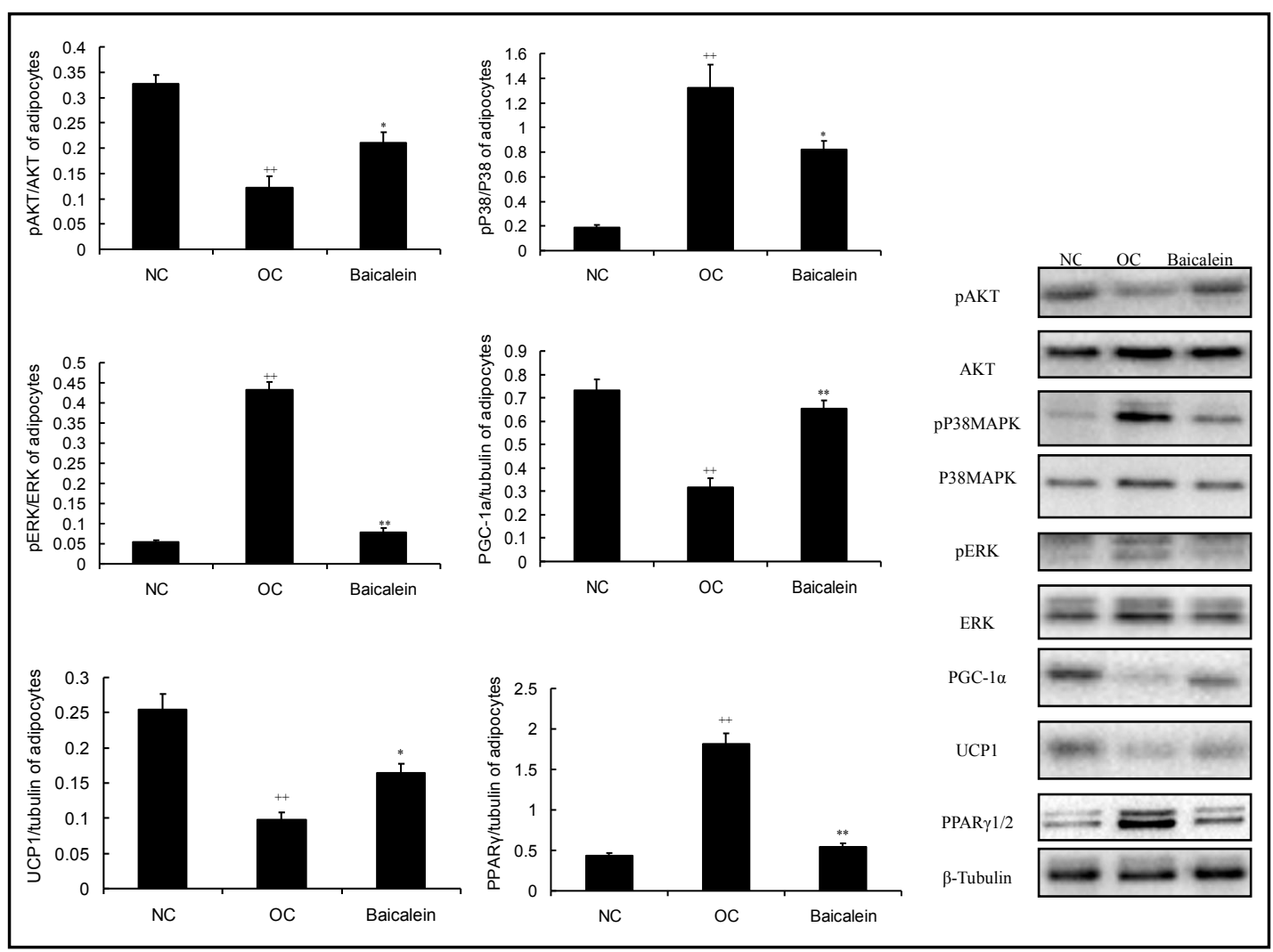

Fig. 9. I.p. injection of baicalein elevated pAKT, PGC- $1 \alpha$ and UCP1 levels, but reduced pP38MAPK, pERK and PPAR $\gamma$ levels of adipocytes ( $n=3$ ). As shown in Fig. 9, the pAkt, PGC1 $\alpha$ and UCP1 contents were enhanced, but the pP38MAPK, pERK and PPAR $\gamma$ contents were reduced in the baicalein group compared with the obese controls (OC) respectively. The pAkt, PGC1 $\alpha$ and UCP1 contents were decreased, but the pP38MAPK, pERK and PPAR $\gamma$ contents were increased in OC compared with normal controls (NC) respectively. The sequence of representative Western blot lines in each panel is NC, OC and Baicalein group. All data shown are the means \pm SEM. ${ }^{*} \mathrm{P}<0.05$ vs. $\mathrm{OC} ;{ }^{* *} \mathrm{P}<0.01$ vs. $\mathrm{OC} ;++\mathrm{P}<0.01$ vs. NC.

The ratios of $p A K T / A K T$, $p P 38 M A P K / P 38 M A P K, p E R K / E R K$ and $P G C-1 \alpha, U C P 1$ as well as $P P A R \gamma$ levels in epididymal fat tissues

As shown in Fig. 9, the ratios of pAKT/AKT and PGC- $1 \alpha$ as well as UCP1 contents were enhanced by $62.6 \%(\mathrm{P}<0.05), 105.6 \%(\mathrm{P}<0.01)$ and $67.3 \%(\mathrm{P}<0.05)$ in baicalein group compared with obese controls, but decreased by $71.9 \%(\mathrm{P}<0.01), 56.7 \%(\mathrm{P}<0.01)$ and $61.4 \%$ $(\mathrm{P}<0.01)$ in obese control group compared with the normal controls, respectively. However, the ratios of pP38MAPK/P38MAPK and $\mathrm{pERK} / \mathrm{ERK}$ as well as PPAR $\gamma$ level were reduced by $37.9 \%(\mathrm{P}<0.05), 81.9 \%(\mathrm{P}<0.01)$ and $70.3 \%(\mathrm{P}<0.01)$ in baicalein group compared with obese controls, but increased by $612.9 \%(\mathrm{P}<0.01), 819.5 \%(\mathrm{P}<0.01)$ and $323.2 \%(\mathrm{P}<0.01)$ in the obese control group compared with the normal controls, respectively.

\section{Discussion}

Baicalein is a bioactive flavonoid isolated from the radix of Scutellaria baicalensis [7, 15]. Recent studies reported that baicalein might play an anti-obesity role $[9,12]$. The supplementation of baicalein $(400 \mathrm{mg} / \mathrm{kg} / \mathrm{d})$ in mice fed with high fat diet for 29 weeks ameliorated the severity of obesity and hyperlipidemia [12]. Furthermore, treatment of 3T3-L1 preadipocytes with baicalein inhibited the intracellular lipid accumulation during 
adipogenesis [16]. In accordance with these, the current results revealed that i.p. injection of baicalein decreased food intake, adipose tissue and body weight of diet-induced obese mice, further indicating that baicalein had the anti-obesity effects. In addition, baicalein appears to induce the expression of many genes associated with thermogenesis. It was found in the present study that the prolonged consumption of high-fat diet led to an increase in the expression of the adipogenic gene PPAR $\gamma$ along with the enhanced phosphorylation of the p38MAPK and ERK proteins in the epididymal adipose tissues of mice. Besides, high-fat diet strongly inhibited the PGC- $1 \alpha$ and UCP1 protein expression in the epididymal adipose tissue. In this study, baicalein treatment led to the inhibition of ERK phosphorylation, resulting in decreased PPAR $\gamma$ expression and increased PGC-1a expression along with a subsequent elevation in UCP1 expression in the epididymal adipose tissue of mice. These results suggested that baicalein treatment led to increased thermogenesis and suppressed adipogenesis, respectively. Taken together, all of these results provided evidence in support of a role for baicalein in anti-obesity effects.

Furthermore, baicalein possessed the potency to ameliorate hyperglycemia and insulin resistance. In vitro, baicalein significantly increased glucose-stimulated insulin secretion in insulin secreting pancreatic INS382/13 cells and human islets culture [8]. Besides, baicalein was reported to have antihyperglycemic effects through the improvement of islet $\beta$-cell survival and mass [8]. Moreover, the supplementation of baicalein $(400 \mathrm{mg} / \mathrm{kg} / \mathrm{d})$ in in mice fed with high fat diet for 29 weeks ameliorated insulin resistance and hyperglycemia through activation of AMPK signaling pathways in liver [12]. In the present study, treatment with baicalein in obese mice significantly decreased AUC and HOMA-IR values compared to the obese controls. These results indicate that baicalein can increase glucose uptake and insulin sensitivity.

Baicalein processes multitherapeutic activities, including anti-oxidant and antiinflammatory properties. Insulin resistance is believed to be the result of chronic low-grade inflammation [17], which activated MAPK kinases, leading to phosphorylation of ERK and P38MAPK and causing insulin resistance of adipocytes [17-20]. In the present study, baicalein significantly reversed the upregulation of pP38MAPK as well as pERK in the adipocytes of diet-induced obese mice. These results suggested that baicalein potently inhibited proinflammatory responses in adipocytes by inhibiting MAP kinase kinases, leading to the decrease of pERK and pP38MAPK levels. Collectively, baicalein exerted its beneficial effects on high fat diet-induced insulin resistance in adipocytes by blocking of MAPKs signaling pathways.

Baicalein significantly reversed the down-regulation of PGC-1 $\alpha$ and GLUT4 in adipocytes of diet-induced obese mice. On one hand, PGC- $1 \alpha$ is a critical regulator of mitochondrial biogenesis in adipocytes and muscles to maintain an energy balance [21, 22]. PGC-1 $\alpha$ can enhance the expression of GLUT4 to increase glucose uptake [23, 24]. Overexpressed PGC$1 \alpha$ increased glucose uptake in adipocytes and muscle [25]. On the other hand, GLUT4 is a particularly important glucose transporter for maintaining glucose homeostasis and insulin sensitivity in response to insulin stimuli. Its translocation from intracellular membrane compartments to plasma membranes is a rate-limiting step of glucose uptake and is closely associated with insulin resistance in adipocytes and skeletal muscle [26]. The current study found that administration of baicalein could upregulate GLUT4 and PGC- $1 \alpha$ levels in adipocytes of diet-induced obese mice, suggesting that administration of baicalein enhanced PGC-1 $\alpha$ levels to boost GLUT4 expression, resulting in the increase in glucose uptake [23, 24]. More interestingly, we found that the GLUT4 contents in the plasma membranes were markedly increased in adipocytes of baicalein-treated diet-induced obese mice, implicating that baicalein not only enhances GLUT4 expression levels, but also accelerates GLUT4 translocation from intracellular membrane compartments to plasma membranes in adipocytes.

To understand the signal mechanism that baicalein promotes GLUT4 translocation, we examined the levels of pAKT in adipocytes of diet-induced obese mice. Activated AKT may prevent insulin resistance through the GLUT4 translocation from intracellular membrane






\section{Cellular Physiology Cell Physiol Biochem 2018;50:426-436 \begin{tabular}{l|l} 
DOI: 10.1159/000494154 & $\begin{array}{l}\text { O } 2018 \text { The Author(s). Published by S. Karger AG, Basel } \\
\text { www.karger.com/cpb }\end{array}$
\end{tabular} \\ Min et al.: Baicalein and Adipocytes}

compartments to plasma membranes in adipocytes [27]. The results in the present study showed that treatment with baicalein enhanced pAkt contents to boost GLUT4 translocation and glucose uptake, suggesting that baicalein increased glucose uptake via the AKT/GLUT4 pathway.

\section{Conclusion}

In summary, our present work provided evidence that baicalein can promote GLUT4 translocation to prevent insulin resistance and type 2 diabetes. The major mechanisms of its action were up-regulation of PGC- $1 \alpha$ and pAKT as well as the down-regulation of pP38MAPK and $\mathrm{pERK}$ in adipocytes. Altogether, these findings indicate that baicalein plays a significant role in regulation of glucose metabolic homeostasis and in elevation of insulin sensitivity to promote glucose clearance. This study contributes to our understanding of the antidiabetic effects of baicalein, and provides a possibility of using baicalein to treat type 2 diabetes in clinic. Further clinical studies are required to establish its clinical utility.

\section{Acknowledgements}

This work was supported by the National Natural Scientific Fund of China (No. 81673736; No. 81803792) and the Natural Scientific Fund of Jiangsu (No. BK20171319) and Qing Lan Project of Jiangsu.

\section{Disclosure Statement}

The authors declared no conflict of interests.

\section{References}

1 Saltiel AR, Kahn CR: Insulin signalling and the regulation of glucose and lipid metabolism. Nature 2001;414:799-806.

-2 Abel ED, Peroni O, Kim JK, Kim YB, Boss O, Hadro E, Minnemann T, Shulman GI, Kahn BB: Adiposeselective targeting of the GLUT4 gene impairs insulin action in muscle and liver. Nature 2001;409:729-733.

3 Carvalho E, Kotani K, Peroni OD, Kahn BB: Adipose-specific overexpression of GLUT4 reverses insulin resistance and diabetes in micelacking GLUT4 selectively in muscle. Am J Physiol Endocrinol Metab 2005;289:E551-E561.

-4 Tozzo E, Gnudi L, Kahn BB: Amelioration of insulin resistance in streptozotocin diabetic mice by transgenic overexpression of GLUT4 driven by an adipose-specific promoter. Endocrinology 1997;138:1604-1611.

-5 Maier VH, Gould GW: Long-term insulin treatment of 3T3-L1 adipocytes results in mis-targeting of GLUT4: implications for insulin-stimulated glucose transport. Diabetologia 2000;43:1273-1281.

-6 Beaton N, Rudigier C, Moest H, Müller S, Mrosek N, Röder E, Rudofsky G, Rülicke T, Ukropec J, Ukropcova B, Augustin R, Neubauer H, Wolfrum C: TUSC5 regulates insulin-mediated adipose tissue glucose uptake by modulation of GLUT4 recycling. Mol Metab 2015;4:795-810.

7 Li HB, Chen F: Isolation and purification of baicalein, wogonin and oroxylin a from the medicinal plant scutellaria baicalensis by high-speed counter-current chromatography. J Chromatogr A 2005;1074:107110.

-8 Fu Y, Luo J, Jia Z, Zhen W, Zhou K, Gilbert E, Liu D: Baicalein Protects against Type 2 Diabetes via Promoting Islet $\beta$-Cell Function in Obese Diabetic Mice. Int J Endocrinol 2014;2014:846742.

-9 Faulkner J, Pye C, Al-Shabrawey M, Elmarakby AA: Inhibition of 12/15-Lipoxygenase Reduces Renal Inflammation and Injury in Streptozotocin-Induced Diabetic Mice. J Diabetes Metab 2015;6:pii:555. 


\section{Cellular Physiology Cell Physiol Biochem 2018;50:426-436

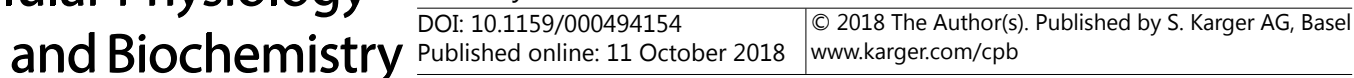 \\ Min et al.: Baicalein and Adipocytes}

10 Ku SK, Bae JS: Baicalin, baicalein and wogonin inhibits high glucose-induced vascular inflammation in vitro and in vivo. BMB Rep 2015;48:519-524.

11 Qi Z, Xu Y, Liang Z, Li S, Wang J, Wei Y, Dong B: Baicalein alters PI3K/Akt/GSK3 $\beta$ signaling pathway in rats with diabetes-associated cognitive deficits. Int J Clin Exp Med 2015;8:1993-2000.

-12 Pu P, Wang XA, Salim M, Zhu LH, Wang L, Chen KJ, Xiao JF, Deng W, Shi HW, Jiang H, Li HL: Baicalein, a natural product, selectively activating $\mathrm{AMPK} \alpha(2)$ and ameliorates metabolic disorder in diet-induced mice. Mol Cell Endocrinol 2012;362:128-138.

13 Chen WC, Kuo TH, Tzeng YS, Tsai YC: Baicalin induces apoptosis in SW620 human colorectal carcinoma cells in vitro and suppresses tumor growth in vivo. Molecules 2012;17:3844-3857.

14 Liang Y, Sheng S, Fang P, Ma Y, Li J, Shi Q, Sui Y, Shi M: Exercise-induced galanin release facilitated GLUT4 translocation in adipocytes of type 2 diabeticrats. Pharmacol Biochem Behav 2012;100:554-559.

15 de Oliveira MR, Nabavi SF, Habtemariam S, Erdogan Orhan I, Daglia M, Nabavi SM: The effects of baicalein and baicalin on mitochondrial function and dynamics: A review. Pharmacol Res 2015;100:296-308.

16 Nakao Y, Yoshihara H, Fujimori K: Suppression of Very Early Stage Of Adipogenesis by Baicalein, a PlantDerived Flavonoid through Reduced Akt-C/EBP $\alpha$-GLUT4 Signaling-Mediated Glucose Uptake in 3T3-L1 Adipocytes. PLoS One DOI:10.1371/journal.pone.0163640.

17 Fujishiro M, Gotoh Y, Katagiri H, Sakoda H, Ogihara T, Anai M, Onishi Y, Ono H, Abe M, Shojima N, Fukushima Y, Kikuchi M, Oka Y, Asano T: Three mitogen-activated protein kinases inhibit insulin signalling by different mechanisms in 3T3-L1 adipocytes. Mol Endocrinol 2003;17:487-497.

-18 Hernandez R, Teruel T, de Alvaro C, Lorenzo M: Rosiglitazone ameliorates insulin resistance in brown adipocytes of Wistar rats by impairing TNF-alpha induction of p38 and p42/p44 mitogen-activated protein kinases. Diabetologia 2004;47:1615-1624.

19 Pearson G, Robinson F, Beers Gibson T, Xu BE, Karandikar M, Berman K: Mitogenactivated protein (MAP) kinase pathways: regulation and physiological functions. Endocr Rev 2001;22:153-183.

-20 Seo MJ, Lee YJ, Hwang JH, Kim KJ, Lee BY: The inhibitory effects of quercetin on obesity and obesityinduced inflammation by regulation of MAPK signaling. J Nutr Biochem 2015;26:1308-1316.

-21 Puigserver P, Adelmant G, Wu Z, Fan M, Xu J, O’Malley B, Spiegelman BM: Activation of PPARg coactivator-1 through transcription factor docking. Science 1999;286:1368-1371.

-22 Wu Z, Puigserver P, Andersson U, Zhang C, Adelmant G, Mootha V, Troy A, Cinti S, Lowell B, Scarpulla RC, Spiegelman BM: Mechanisms controlling mitochondrial biogenesis and respiration through the thermogenic coactivator PGC-1. Cell 1999;98:115-124.

23 Wright DC, Han DH, Garcia-Roves PM, Geiger PC, Jones TE, Holloszy JO: Exercise-induced mitochondrial biogenesis begins before the increase in muscle PGC-1alpha expression. J Biol Chem 2007;282:194-199.

24 Wu H, Deng X, Shi Y, Su Y, Wei J, Duan H: PGC-1 $\alpha$, glucose metabolism and type 2 diabetes mellitus. J Endocrinol 2016;229:R99-R115.

-25 Michael LF, Wu Z, Cheatham RB, Puigserver P, Adelmant G, Lehman JJ, Kelly DP, Spiegelman BM: Restoration of insulin-sensitive glucose transporter (GLUT4) gene expression in muscle cells by the transcriptional coactivator PGC-1. Proc Natl Acad Sci USA 2001;98:3820-3825.

-26 Leto D, Saltiel AR: Regulation of glucose transport by insulin: traffic control of GLUT4. Nat Rev Mol Cell Biol 2012;13:383-396.

-27 Sakamoto K, Holman GD: Emerging role for AS160/TBC1D4 and TBC1D1 in the regulation of GLUT4 traffic. Am J Physiol 2008;295:E29-E37. 